\title{
Percutaneous treatment with Mitraclip for functional mitral regurgitation: medium-term follow up according to left ventricular function
}

\author{
Isaac Pascual ${ }^{1,2,3}$, Tomás Benito-González ${ }^{4}$, Daniel Hernandez-Vaquero ${ }^{1,2,3}$, Rodrigo Estévez-Loureiro ${ }^{5}$, \\ Rebeca Lorca ${ }^{1,2}$, Carmen Garrote-Coloma ${ }^{4}$, Pablo Avanzas ${ }^{1,2,6}$, Javier Gualis ${ }^{7}$, Antonio Adeba ${ }^{1,2}$, \\ Armando Pérez de Prado ${ }^{4}$, César Morís ${ }^{1,2,6}$, Felipe Fernández-Vázquez ${ }^{4}$ \\ ${ }^{1}$ Heart Area, Hospital Universitario Central de Asturias, Oviedo, Spain; ${ }^{2}$ Instituto de Investigación Sanitaria del Principado de Asturias, Oviedo, \\ Spain; ${ }^{3}$ Functional Biology Department, University of Oviedo, Oviedo, Spain; ${ }^{4}$ Department of Cardiology, University Hospital of León, León, Spain; \\ ${ }^{5}$ Department of Cardiology, Hospital Alvaro Cunqueiro, Vigo, Spain; ${ }^{6}$ Medicine Department, University of Oviedo, Oviedo, Spain; ${ }^{7}$ Department of \\ Cardiac Surgery, University Hospital of León, León, Spain \\ Contributions: (I) Conception and design: All authors; (II) Administrative support: All authors; (III) Provision of study materials or patients: All \\ authors; (IV) Collection and assembly of data: All authors; (V) Data analysis and interpretation: All authors; (VI) Manuscript writing: All authors; (VII) \\ Final approval of manuscript: All authors. \\ Correspondence to: Daniel Hernandez-Vaquero, MD, PhD. Heart Area, Hospital Universitario Central de Asturias, Oviedo, Spain. \\ Email: dhvaquero@gmail.com
}

Background: Functional mitral regurgitation (FMR) is a bad prognosis condition despite optimal medical treatment. Nowadays there is an open debate about the surgical versus percutaneous treatment. The main objective of this study is to evaluate the mid-term follow up clinical outcomes of patients with FMR treated with MitraClip ${ }^{\circledR}$ system, according to their left ventricular ejection fraction (LVEF).

Methods: Data was obtained from two experienced centers in transcatheter mitral valve repair (TMVR). All consecutive cases of severe FMR undergoing TMVR in both centers with the same inclusion criteria were included prospectively in this study and followed-up. Periodical follow-ups with clinical and echocardiographic evaluation were scheduled from the baseline procedure, at 3 months and then yearly.

Results: From October 2015 to October 2019, a total of 119 patients with FMR at 2 centers in Spain underwent TMVR with the MitraClip ${ }^{\circledR}$ procedure and were included in this study. The mean age was $73.8 \pm 8.9$ years old and 32 patients $(26.9 \%$ ) were female. A $39.5 \%$ of cases [47] had a LVEF $\leq 30 \%$ (group 1) and $60.5 \%$ (72 cases) had a LVEF $>30 \%$ (group 2). There was a similar distribution in cardiovascular risk factors, age and other diseases. All MitraClip ${ }^{\circledR}$ implantations were elective and procedural success was achieved in 110 patients $(92.4 \%)$ with a similar distribution between the groups. There were no differences in procedural time and the number of implanted clips. The median follow-up was 22.6 months (IQR, 11.4334.98 months). The primary combined endpoint occurred in the $41.6 \%$ of the global cohort, $57.5 \%$ in group 1 and $30.99 \%$ in group $2(\mathrm{P}=0.036)$. $\mathrm{LVEF}$ was associated to the main event in the multivariate analysis (HR 2.09, 95\% CI: $1.12-3.89 ; \mathrm{P}=0.02)$.

Conclusions: The MitraClip edge-to-edge technique is a safe and effective procedure for the treatment of FMR. In this study, patients with LVEF $>30 \%$ treated with Mitraclip presented better clinical cardiovascular outcomes than those with a LVEF $\leq 30 \%$. Regardless clinical outcomes, at the end of the follow-up, there was a sustained reduction in MR grades and an important improvement in NYHA functional class.

Keywords: Functional; mitral regurgitation; Mitraclip; left ventricular function

Submitted Dec 19, 2019. Accepted for publication Feb 15, 2020.

doi: 10.21037/atm.2020.02.122

View this article at: http://dx.doi.org/10.21037/atm.2020.02.122 


\section{Introduction}

Mitral regurgitation (MR) is one of the most prevalent valvular disease and the second most frequent indication for valve surgery in Europe $(1,2)$. Therapeutic approach (i.e., surgical or percutaneous repair) varies depending on MR etiology. Therefore, it is imperative to discriminate properly between its different etiological mechanisms. On the one hand, if the components of the mitral valve apparatus (e.g., leaflets, chordae or papillary muscles) are directly affected, causing $M R$, it is considered a primary or organic MR (PMR). On the other hand, in secondary or functional MR (FMR) there is a lack of coaptation of the leaflets mainly due to left ventricular (LV) or annulus dilation, preserving the components of the mitral apparatus intact $(3,4)$.

Patients with symptomatic MR, if left untreated, present higher rates of cardiovascular mortality and hospitalizations due to heart failure (HF) as well as an impaired quality of life $(5,6)$. Surgical repair of PMR can correct the source of the valvular disease problem. As a result, $L V$ volume overload is reduced and the prognosis of the patient improves $(7,8)$. On the contrary, FRM is controversial. It is still unclear whether if the impaired prognosis in FMR is mainly due the primary disease of the LV or whether in fact FRM itself implies a vital prognostic factor. However, owing to the fact that patients with $\mathrm{LV}$ dysfunction and FMR have a worse prognosis than patients with LV dysfunction alone (9), it is suspected that FMR may actually play a role in determining prognosis. Nonetheless, there is no evidence to date supporting the hypothesis that repair of FMR could reverse the pathophysiology of the underlying $\mathrm{LV}$ disease or if it could actually improve the final prognosis $(8,10)$.

In current European Guidelines (10), surgery is indicated in all symptomatic PMR patients with $\mathrm{LV}$ ejection fraction (LVEF) $>30 \%$ (class I, level of evidence B). A LVEF) $\leq 60 \%$ and left ventricular end-systolic diameter (LVESD) $\geq 45 \mathrm{~mm}$ are known to predict a worse postoperative outcome, independent of the symptomatic status (11). Thus, if severe $\mathrm{LV}$ dysfunction (LVEF $<30 \%$ and/or LVESD $>55 \mathrm{~mm}$ ) is present, the class of recommendation lowers to class II (IIa if reparable; IIb if mitral valve replacement is needed, level of evidence C) (10). Conversely, in chronic severe FMR symptomatic patients, despite optimal medical management and when revascularization is not indicated, surgery may be considered if surgical risk is low or percutaneous edge-toedge procedure if the surgical risk is higher, striking with the same level of recommendation (class IIb, of evidence level C) regardless LVEF (10).
Transcatheter mitral valve repair (TMVR) using MitraClip ${ }^{\circledR}$ (Abbott Vascular, Menlo Park, California) system was initially approved for the treatment of PMR. Nevertheless, in recent European registries, 65.2-77.1\% of the patients were treated for severe symptomatic FMR, with promising data in procedural success $(94-99.1 \%)$ and a sustained MR reduction to a grade 2 or less (12-16). These data suggest that MitraClip ${ }^{\circledR}$ could be a promising alternative option for the treatment of such a complex disease. Thus, there are two large randomized controlled trials available comparing TMVR plus medical therapy versus medical therapy alone in FMR patients: the COAPT trial (17) and the MITRA-FR trial (18). Despite their high rates of procedure success, different clinical results in follow-up were found.

The main objective of this study is to evaluate the clinical outcomes of patients with FMR treated with MitraClip ${ }^{\circledR}$ system, according to their LVEF.

\section{Methods}

All patients moderate-severe or severe ( 3 to $4+$ ) FMR, symptomatic despite guideline-directed optimal medical therapy, were evaluated by a multidisciplinary Heart Team (comprising interventional cardiologists, cardiac surgeons, HF specialized cardiologists and cardiac imaging specialists). The severity of MR was evaluated by experts cardiac imaging specialists, according to ESC guidelines criteria (10). Patients who fulfilled echocardiographic criteria of eligibility for TMVR and who were not surgical candidates were included. TMVR was performed with the MitraClip ${ }^{\circledR}$ edge to edge technique as reported elsewhere (19). Informed consent was obtained from all patients.

FMR cases undergoing MitraClip ${ }^{\circledR}$ implantation were divided into two groups according to LVEF: group 1: patients with severely impaired LVEF (LVEF less or equal to $30 \%$ ); and group 2: patients with LVEF $>30 \%$. All outcomes were defined according to Valve Academic Research Consortium-2 criteria (20). Procedural success was defined as a correct release of at least one device and a MR reduction to a grade $2+$ or less.

Data was obtained from two experienced centers in TMVR. All consecutive cases of FMR undergoing TMVR in both centers with the same explained inclusion criteria were included in this study, and prospectively followed-up. Periodical follow-ups with clinical and echocardiographic evaluation were scheduled from the baseline procedure, at 3 months and then yearly. There were no loses reported. 


\section{Endpoints}

The primary combined endpoint included $\mathrm{HF}$ hospitalizations and all-cause mortality at the end of the follow-up. The primary endpoints HF hospitalizations and all-cause mortality were also analyzed separately. The secondary endpoints were improvement in NYHA class and the absence of severe MR at the end of the follow-up. Bleeding, as a safety endpoint, was defined according to the Bleeding Academic Research Consortium (BARC) (21). Major bleeding was defined as BARC types 3 and 5 .

\section{Statistical analysis}

Continuous variables are reported as mean \pm standard deviation (SD) in case of normal distribution and median, 25 th to 75 th interquartile range (IQR) otherwise. Normal distribution was assessed by the Kolmogorov-smirnov test. Categorical variables are expressed as percentages). Chisquared was used to compare categorical variables and paired Student's $t$-test for continuous variables. Time to event curves were calculated using Kaplan-Meier curves and Univariable Cox proportional hazard model was used to identify the factors associated with the primary endpoint calculating the HR with its $95 \%$ CI. A P value of $<0.05$ was considered statistically significant. Statistical analysis was performed using Stata 15.2 (Stata Corp., LP, USA).

\section{Results}

\section{Baseline characteristics}

From October 2015 to October 2019, a total of 119 patients with FMR at 2 centers in Spain underwent TMVR with the MitraClip ${ }^{\circledR}$ procedure and were included in this study. The mean age was $73.8 \pm 8.9$ years old and 32 patients $(26.9 \%)$ were female. A $39.5 \%$ of cases [47] had a LVEF $\leq 30 \%$ (group 1) and 60.5\% (72 cases) had a LVEF >30\% (group 2). There was a similar distribution in cardiovascular risk factors, age and other diseases, as well as similar levels of NTproBNP among groups. There were no other significant differences between groups in Euroscore I, Euroscore II and STS scores. However, ICD/CRT implantation rate, as could be expected due to their worse LVEF, was higher in group $1(42.5 \%$ vs. $15.3 \%, \mathrm{P}<0.0001)$. Detailed baseline characteristics are shown in Table 1.

Severe mitral regurgitation was present in over $90 \%$ of the cases in both groups $(\mathrm{P}=0.82)$. Significant differences between groups in the baseline LVEF (24.7\% group $1 v s$.
44.5\% group 2, $\mathrm{P}<0.0001$ ), LVEDD (66.9 vs. $58.7 \mathrm{~mm}$, $\mathrm{P}<0.0001)$ and $\mathrm{LV}$ end-diastolic volume (LVEDV) $(179.2$ vs. $137.0 \mathrm{~mL}, \mathrm{P}<0.0001)$ were found. Nonetheless, ischemic MR etiology had non-significant difference in its prevalence between groups $(40.4 \%$ vs. $56.9 \%, \mathrm{P}=0.065)$. Complete baseline echocardiographic data are shown in Table 1.

\section{Procedure}

All MitraClip ${ }^{\circledR}$ implantations were elective and procedural success was achieved in 110 patients $(92.4 \%)$ with a similar distribution between the groups. Similarly, there were no differences in procedural time and the number of implanted clips. There were only $4(3.36 \%)$ cases of detachment and 2 cases that required mitral repair/replacement surgery, both from group 2 . There was only 1 case, in group 1 , which required a second TMVR procedure. In-hospital complications were low, with no cases of intraprocedural deaths, no vascular complications and bleeding cases according to BARC definitions (21).

\section{Primary endpoint}

The median follow-up was 22.6 months (IQR, 11.43-34.98 months). The primary combined endpoint occurred in the $41.6 \%$ of the global cohort, $57.5 \%$ in group 1 and $30.99 \%$ in group $2(\mathrm{P}=0.036)$. HF hospitalization was significant $(\mathrm{P}=0.001)$ higher in group $1(51.1 \%)$ than in in group 2 (20.8\%). However, percentage of all-cause mortality was similar in both groups. Details of the primary endpoint can be seen in Table 2. Figure $1 A, B$ and $C$ show Kaplan-Meier curves detailing the main events and Table 3 shows the univariate and multivariate analysis.

The variables associated with the primary endpoint at univariate analysis were a higher STS, Euroscore and Euroscore II risk scores, previous Coronary artery bypass grafting surgery, chronic kidney disease, worse LVEF, hypertension, dyslipidemia and diabetes. However, only LVEF was associated to the main event in the multivariate analysis (HR 2.09, 95\% CI: 1.12-3.89, $\mathrm{P}=0.02$ ).

\section{Secondary endpoints}

At the baseline evaluation $89.92 \%$ of the patients were in functional class NYHA III and improved to a NYHA stage I or II in $82.35 \%$ of the cases. At the end of the follow-up period, only $17.5 \%$ of patients were in NYHA stage III or $\mathrm{IV}$, with a non-significant tendency favoring group $2(12.5 \%$ 
Table 1 Baseline characteristics and procedural data

\begin{tabular}{|c|c|c|c|c|}
\hline Variable & Total $(n=119)$ & Group 1: LVEF $\leq 30 \%(n=47)$ & Group 2: LVEF >30\% $(n=72)$ & $\mathrm{P}$ \\
\hline Female sex & $32(26.9 \%)$ & $13(27.7 \%)$ & $19(26.4 \%)$ & 0.879 \\
\hline $\operatorname{BIM}\left(\mathrm{kg} / \mathrm{m}^{2}\right)$ & $27.1 \pm 0.43$ & $27.3 \pm 0.7$ & $26.9 \pm 0.5$ & 0.6014 \\
\hline HTA & $83(69.8 \%)$ & $31(65.9 \%)$ & $52(72.2 \%)$ & 0.467 \\
\hline Dyslipidemia & $62(52.1 \%)$ & $25(53.2 \%)$ & $37(51.4 \%)$ & 0.847 \\
\hline CKD & $56(47.1 \%)$ & $20(42.6 \%)$ & $36(50 \%)$ & 0.426 \\
\hline Stroke & $21(17.7 \%)$ & $8(17 \%)$ & $13(18.1 \%)$ & 0.708 \\
\hline PAD & $14(11.8 \%)$ & $3(6.4 \%)$ & $11(15.3 \%)$ & 0.141 \\
\hline $\mathrm{PCl}$ & $49(41.2 \%)$ & $16(34.0 \%)$ & $33(45.8 \%)$ & 0.201 \\
\hline CABG & $16(13.4 \%)$ & $5(10.6 \%)$ & $11(15.3 \%)$ & 0.468 \\
\hline AF & $74(62.2 \%)$ & $45(95.7 \%)$ & $29(40.3 \%)$ & 0.93 \\
\hline IAD & $31(26.1 \%)$ & $20(48.8 \%)$ & $11(15.3 \%)$ & 0.0001 \\
\hline NTproBNP & $4,855.6 \pm 6,132.8$ & $3,903.5 \pm 3,289.3$ & $5,529.4 \pm 7,478.1$ & 0.1699 \\
\hline Log Euroscore I & $19.78 \pm 14.3$ & $20.6 \pm 14.4$ & $19.3 \pm 14.3$ & 0.6328 \\
\hline Euroscore II & $7.74 \pm 8.16$ & $8.1 \pm 7.68$ & $7.49 \pm 8.5$ & 0.6882 \\
\hline LA diameter (mm) & $50.1 \pm 1.4$ & $49.6 \pm 1.6$ & $50.3 \pm 1.9$ & 0.8128 \\
\hline LA area $\left(\mathrm{cm}^{2}\right)$ & $27.7 \pm 0.7$ & $27.0 \pm 0.8$ & $28.1 \pm 1.1$ & 0.477 \\
\hline LA volume (mL) & $112.1 \pm 4.4$ & $111.3 \pm 5.6$ & $112.6 \pm 6.3$ & 0.883 \\
\hline LV Strain (\%) & $12.7 \pm 0.6$ & $9.9 \pm 0.9$ & $13.85 \pm 0.7$ & 0.0039 \\
\hline TAPSE & $17.6 \pm 0.6$ & $16.5 \pm 1.1$ & $18.2 \pm 0.6$ & 0.1624 \\
\hline RVEDD (mm) & $43.0 \pm 1.0$ & $43.0 \pm 1.7$ & $43.1 \pm 1.2$ & 0.977 \\
\hline Severe PAH & $31(26.1 \%)$ & $10(21.3 \%)$ & $21(29.2 \%)$ & 0.496 \\
\hline $\begin{array}{l}\text { Medium gradient after PMVR } \\
(\mathrm{mmHg})\end{array}$ & $3.4 \pm 0.2$ & $3.0 \pm 0.2$ & $3.6 \pm 2.7$ & 0.1068 \\
\hline \multicolumn{5}{|l|}{ Procedure } \\
\hline Clips number & $1.44 \pm 0.1$ & $1.42 \pm 0.1$ & $1.44 \pm 0.1$ & 0.8686 \\
\hline XTR clips & $52(43.7 \%)$ & $19(40.4 \%)$ & $33(45.8 \%)$ & 0.561 \\
\hline
\end{tabular}

Table 1 (continued) 
Table 1 (continued)

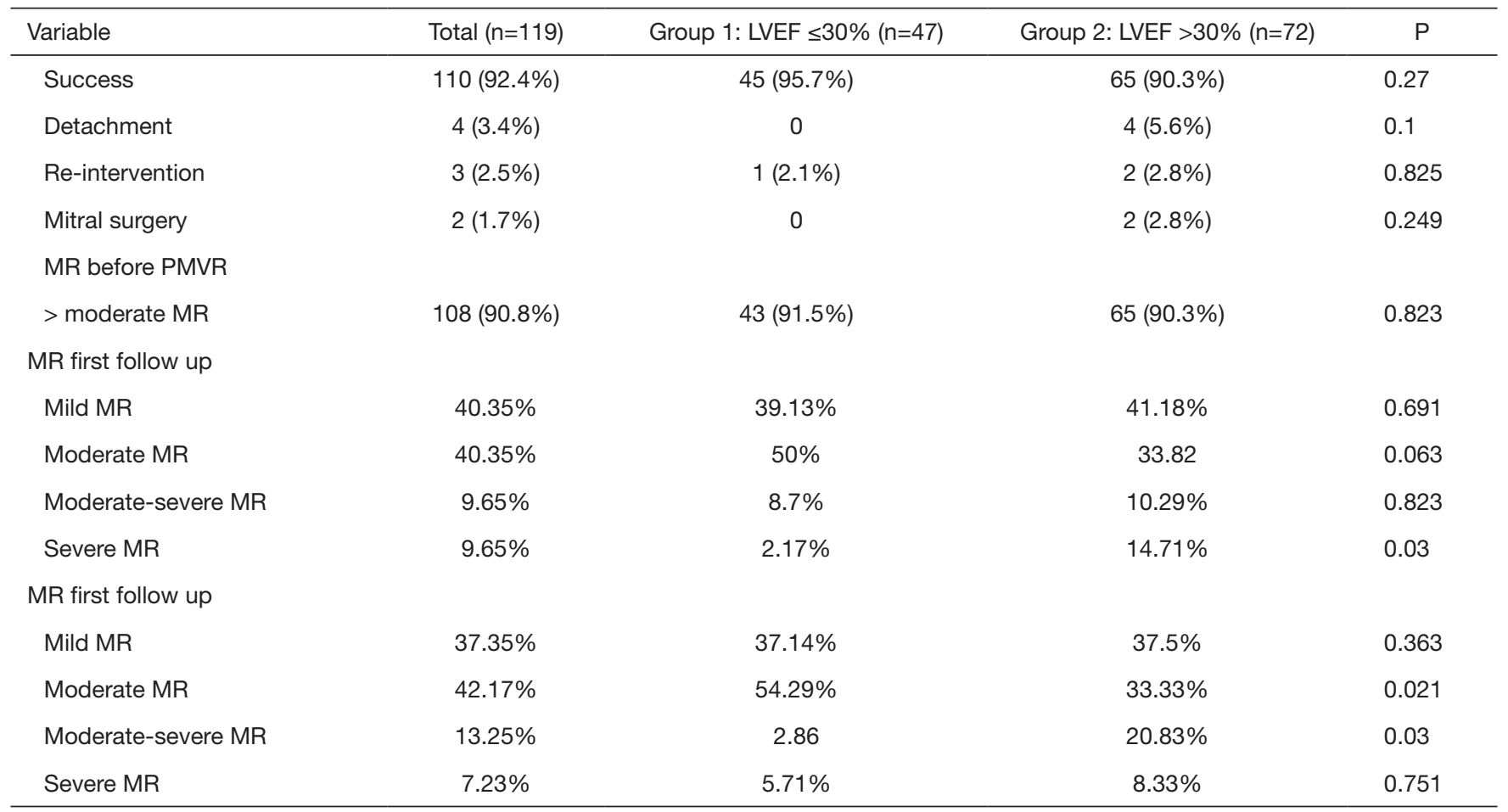

LVEF, left ventricular ejection fraction; BIM, body index mass; HTA, hypertension; CKD, chronic kidney disease; PAD, peripheral artery disease; COPD, chronic obstructive pulmonary disease; DCM, dilated cardiomyopathy; CAD, coronary artery disease; PCI, percutaneous coronary intervention; CABG, coronary artery bypass grafting; AF, atrial fibrillation; IAD, implantable automatic defibrillator, LVEDD, left ventricle end diastolic diameter; LVEDV, left ventricle end diastolic volume, LA, left atrium; TAPSE, tricuspid annular longitudinal excursion; RVEDD, right ventricle end diastolic diameter; PAH, pulmonary arterial hypertension; PMVR, percutaneous mitral valve repair.

Table 2 Detailed primary endpoint

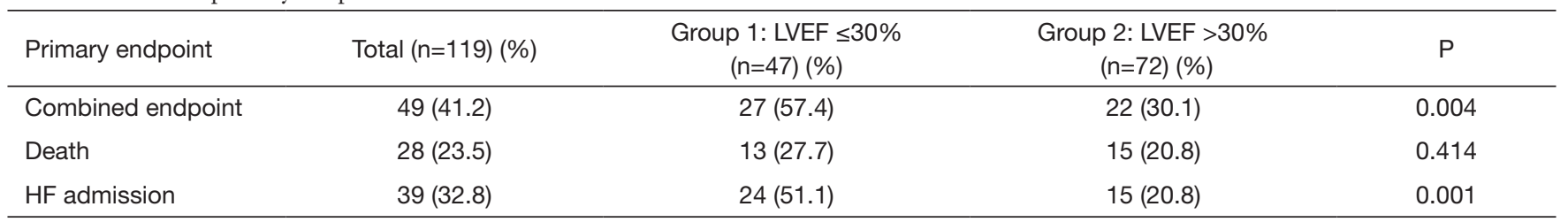

LVEF, left ventricular ejection fraction; HF, hear failure.

vs. $25.5 \%, \mathrm{P}=0.06)$.

Basal severe MR was found in $90.1 \%$ of the cases, representing ischemic MR the $50.1 \%$ of them. Immediately after TMVR procedure, $79.5 \%$ achieved a grade II or less MR. Besides, a sustained reduction in MR was seen at the end of the follow-up, with only a $20.48 \%$ of the patients with grade III-IV MR, similarly in both groups.

\section{Discussion}

On the one hand, the COAPT trial results support the high rates of procedure success (98\%), a persisting $<3$ grade residual MR after the procedure and an improvement in measures of quality of life such as I-II NYHA functional class (22). Moreover, COAP trial endpoints were significantly improved in the MitraClip group compared to controls (mortality and HF hospitalization) (22). Moreover, the outcomes at 3-year follow-up of the COAPT trial were presented at TCT congress 2019, maintaining the benefits on the primary endpoint and mortality (17). On the other hand, the MITRA-FR trial also had good rates of procedure success and reduction of MR grade. Conversely, mortality 

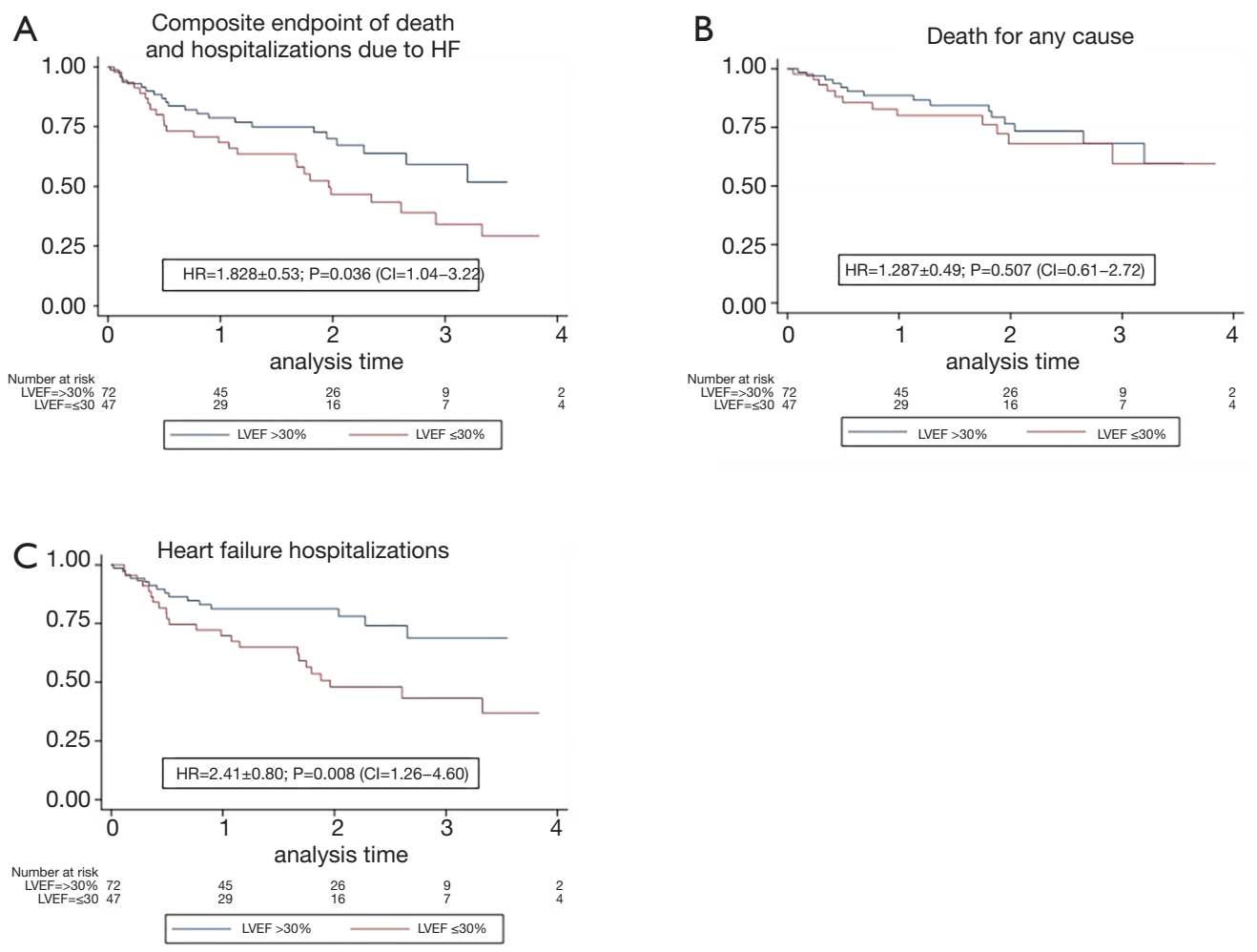

Figure 1 Primary and secondary endpoints graphics: Kaplan-Meier survival curves for the primary endpoint of combined event of death from all-causes and hospitalizations due to heart failure (A), the secondary end point of death for any cause (B) and heart failure hospitalizations (C). HF, heart failure; HR, hazard ratio; LVEF, left ventricle ejection fraction.

and HF hospitalization at 12 -month were similar both in Mitraclip and in directed medical therapy arms (18). This, there was no significant improvement in NYHA functional class either.

Despite the overall similarities in trial designs, there were important differences that may explain the disparate results between COAPT and MITRA-FR trials. Patients from COAPT trial had a more severe degree of MR and less advanced left ventricular disease (COAPT excluded patients with a LV end-diastolic diameter (LVEDD) $>70 \mathrm{~mm}$ and LV ejection fraction $<20 \%$ ). In addition, the COAPT study had a longer follow-up, a more rigorous control in the administration of optical medical therapy and a lower rate of moderate or severe MR at 1 year follow-up.

In the line of previous trials, our present study also shows that the treatment of FMR with the MitraClip ${ }^{\circledR}$ edge-toedge technique is a feasible procedure, with a high rate of success, low rate of complications before discharge and a sustained reduction in the rates of MR after one year of follow-up (presenting most patients a grade $2+$ or less of
MR). Moreover, an important improvement in NYHA functional class after MitraClip ${ }^{\circledR}$ implantation was shown, with $82.3 \%$ of the cases in NYHA II or less functional class. When analyzing echocardiographic data, patients from group 1 not only presented a significant worse LVEF than those from group $2(24.7 \% v s$. $44.5 \%)$, but also an overall significant worse LV measurements (LVEDD of $66.9 \mathrm{vs.}$ $58.7 \mathrm{~mm}$ and LVEDV of 179.2 vs. $137 \mathrm{~mL}$ ).

However, the differences found in primary endpoints between our groups, based on LVEF, can be considered the most important finding of this study. Patients from group 1 with a LVEF $\leq 30 \%$ presented worse clinical cardiovascular outcomes than those with a LVEF $>30 \%$, with a significant higher combined endpoint $(57.5 \%$ vs. $31 \%)$ and higher rate of HF hospitalizations (51.1\% vs. $21.1 \%$ ).

Interestingly, primary endpoints data found in group 1 with LVEF $\leq 30 \%$ (combined endpoint $57.5 \%$, all-cause death $27.7 \%$ and HF hospitalizations $51.1 \%$ ) showed similar rates to those found in the Mitra-FR trial (54.6\%, $24.3 \%$ and $51.06 \%$, respectively) (18). Moreover, the 
Table 3 Multivariate and univariate analysis

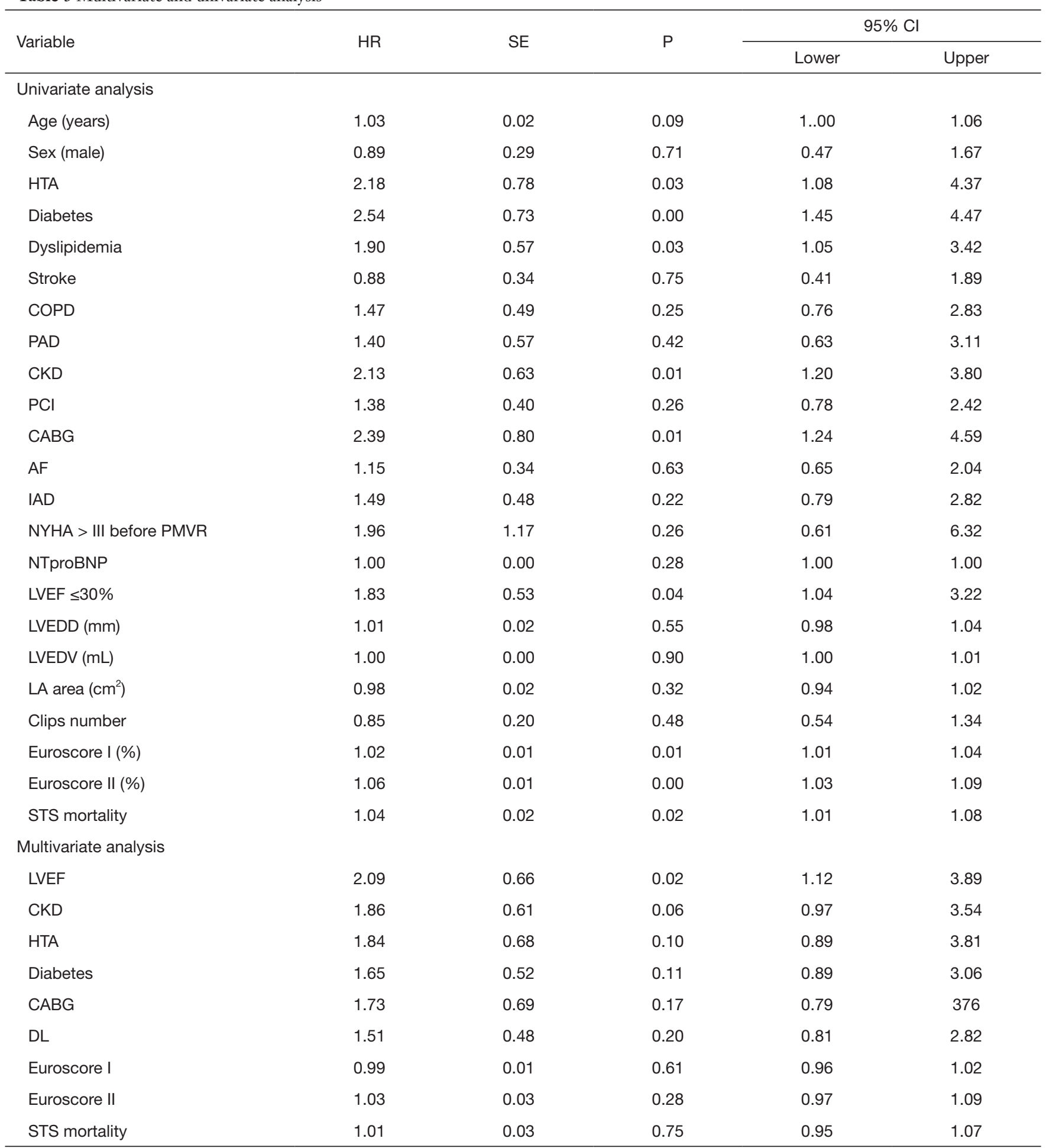

HR, hazard ratio; HTA, hypertension; COPD, chronic obstructive pulmonary disease; PAD, peripheral artery disease; CKD, chronic kidney disease; PCI, percutaneous coronary intervention; CABG, coronary artery bypass grafting; AF, atrial fibrillation; IAD, implantable automatic defibrillator; LVEF, left ventricular ejection fraction; LVEDD, left ventricle end diastolic diameter; LVEDV, left ventricle end diastolic volume; LA, left atrium; TAPSE, tricuspid annular longitudinal excursion; RVEDD, right ventricle end diastolic diameter; PAH, pulmonary arterial hypertension; PMVR, percutaneous mitral valve repair. 
COAPT trial showed similar results in the combined endpoint (33.9\% COAPT vs. 31\% group 2) and all-cause death $(19.1 \%$ vs. $21.1 \%)$ to those found in the group 2 (22).

This similarity should be interpreted with caution, as a formal comparison is not possible. However, it may reveal that patients with less advanced left ventricular disease could be the ones who would benefit more from the procedure, at least in survival and HF hospitalization terms. In fact, it has already been suggested that responders to mitral valve intervention were more likely to have a less advance LV disease or a disproportionate MR to LVEDV based on MITRA-FR and COAPT data (23).

In addition, a recent study by Sanchis et al. that compared MitraClip treatment in FMR patients with poor LV (LVEDD $<70 \mathrm{~mm}$ and LVEF $>20 \%$ ) with those with very poor LV (LVEDD $>70 \mathrm{~mm}$ and LVEF <20\%) also supports this hypothesis (24). Patients with better LV parameters also presented significantly better cardiovascular outcomes (combination of HF Hospitalizations, heart transplant and cardiovascular death). Nevertheless, like in our study, a reduction in symptoms and an improvement in functional class were also found in both groups.

All these findings support the theory that in functional MR the underlying LV disease is the cornerstone that mainly determines the global prognosis. However, larger studies analyzing this hypothesis and looking for precise cut-off points are imperative. This may led to settle a different class of recommendation, based on LV parameters, in the forthcoming guidelines, as already given for LVEF in PMR.

\section{Limitations}

The main limitations of the present study are that it is an observational two-center experience, with a limited patient population and the data analysis was performed in a retrospective manner. These findings should not define causality and further randomized controlled trials should confirm these outcomes.

\section{Conclusions}

The MitraClip edge-to-edge technique is a safe and effective procedure for the treatment of FMR. In this study, patients with LVEF $>30$ treated with TMVR presented better clinical cardiovascular outcomes (a reduced the risk of death and hospitalization for heart HF) than those with a LVEF $\leq 30 \%$. However, regardless clinical outcomes, at the end of the follow-up, there was a sustained reduction in MR grades and an important improvement in NYHA functional class.

\section{Acknowledgments}

Funding: None.

\section{Footnote}

Provenance and Peer Review: This article was commissioned by the Guest Editor (Daniel Hernández-Vaquero) for the series "Structural Heart Disease: The Revolution" published in Annals of Translational Medicine. The article was sent for external peer review organized by the Guest Editor and the editorial office.

Conflicts of Interest: All authors have completed the ICMJE uniform disclosure form (available at http://dx.doi. org/10.21037/atm.2020.02.122). The series "Structural Heart Disease: The Revolution" was commissioned by the editorial office without any funding or sponsorship. CGC reports personal fees from ABBOT VASCULAR, outside the submitted work. REL reports personal fees from ABBOT VASCULAR, outside the submitted work. TBG reports grants from ABBOT VASCULAR, outside the submitted work. DHV served as the unpaid Guest Editor of the series and serves as an unpaid editorial board member of Annals of Translational Medicine from Aug 2019 to Jul 2021. The authors have no other conflicts of interest to declare.

Ethical Statement: The authors are accountable for all aspects of the work in ensuring that questions related to the accuracy or integrity of any part of the work are appropriately investigated and resolved. The study was conducted in accordance with the Declaration of Helsinki (as revised in 2013). The study was approved by the corresponding IRB (reference number: 2020/026). Informed consent was obtained from all patients.

Open Access Statement: This is an Open Access article distributed in accordance with the Creative Commons Attribution-NonCommercial-NoDerivs 4.0 International License (CC BY-NC-ND 4.0), which permits the noncommercial replication and distribution of the article with the strict proviso that no changes or edits are made and the original work is properly cited (including links to both the formal publication through the relevant DOI and the license). See: https://creativecommons.org/ 
licenses/by-nc-nd/4.0/.

\section{References}

1. Iung B, Vahanian A. Epidemiology of acquired valvular heart disease. Can J Cardiol 2014;30:962-70.

2. Iung B, Baron G, Butchart EG, et al. A prospective survey of patients with valvular heart disease in Europe: The Euro Heart Survey on valvular heart disease. Eur Heart J 2003;24:1231-43.

3. Asgar AW, Mack MJ, Stone GW. Secondary mitral regurgitation in heart failure: Pathophysiology, prognosis, and therapeutic considerations. J Am Coll Cardiol 2015;65:1231-48.

4. Zoghbi WA, Adams D, Bonow RO, et al. Recommendations for Noninvasive Evaluation of Native Valvular Regurgitation: A Report from the American Society of Echocardiography Developed in Collaboration with the Society for Cardiovascular Magnetic Resonance. J Am Soc Echocardiogr 2017;30:303-71.

5. Sannino A, Smith RL, Schiattarella GG, et al. Survival and cardiovascular outcomes of patients with secondary mitral regurgitation: A systematic review and metaanalysis. JAMA Cardiol 2017;2:1130-9.

6. Goliasch G, Bartko PE, Pavo N, et al. Refining the prognostic impact of functional mitral regurgitation in chronic heart failure. Eur Heart J 2018;39:39-46.

7. David TE, Armstrong S, McCrindle BW, et al. Late outcomes of mitral valve repair for mitral regurgitation due to degenerative disease. Circulation 2013;127:1485-92.

8. Grayburn PA, Carabello B, Hung J, et al. Defining "severe" secondary mitral regurgitation: Emphasizing an integrated approach. J Am Coll Cardiol 2014;64:2792-801.

9. Deja MA, Grayburn PA, Sun B, et al. Influence of mitral regurgitation repair on survival in the surgical treatment for ischemic heart failure trial. Circulation 2012;125:2639-48.

10. Baumgartner H, Falk V, Bax JJ, et al. 2017 ESC/EACTS Guidelines for the management of valvular heart disease. Eur Heart J 2017;38:2739-91.

11. Enriquez-Sarano M, Tajik AJ, Schaff HV, et al. Echocardiographic prediction of survival after surgical correction of organic mitral regurgitation. Circulation 1994;90:830-7.

12. Pascual I, Arzamendi D, Carrasco-Chinchilla F, et al. Transcatheter mitral repair according to the cause of mitral regurgitation: Real-life data from the Spanish MitraClip registry. Rev Esp Cardiol (Engl Ed) 2020;73:643-51.

13. Maisano F, Franzen O, Baldus S, et al. Percutaneous mitral valve interventions in the real world: Early and 1-year results from the ACCESS-EU, A prospective, multicenter, nonrandomized post-approval study of the Mitraclip therapy in Europe. J Am Coll Cardiol 2013;62:1052-61.

14. Nickenig G, Estevez-Loureiro R, Franzen O, et al. Percutaneous mitral valve edge-to-edge Repair: Inhospital results and 1-year follow-up of 628 patients of the 2011-2012 pilot European Sentinel Registry. J Am Coll Cardiol 2014;64:875-84.

15. Puls M, Lubos E, Boekstegers P, et al. One-year outcomes and predictors of mortality after MitraClip therapy in contemporary clinical practice: Results from the German transcatheter mitral valve interventions registry. Eur Heart J 2016;37:703-12.

16. Baldus S, Schillinger W, Franzen O, et al. Mitra Clip therapy in daily clinical practice: Initial results from the German transcatheter mitral valve interventions (TRAMI) registry. Eur J Heart Fail 2012;14:1050-5.

17. Anon. COAPT: 3-Year Outcomes From a Randomized Trial of the MitraClip in Patients With Heart Failure and Severe Secondary Mitral Regurgitation I tctmd.com.

18. Obadia JF, Messika-Zeitoun D, Leurent G, et al. Percutaneous Repair or Medical Treatment for Secondary Mitral Regurgitation. N Engl J Med 2018;379:2297-306.

19. Feldman T, Foster E, Glower DD, et al. Percutaneous Repair or Surgery for Mitral Regurgitation. N Engl J Med 2011;364:1395-406.

20. Sénage T, Le Tourneau T, Foucher Y, et al. Early structural valve deterioration of mitroflow aortic bioprosthesis: Mode, incidence, and impact on outcome in a large cohort of patients. Circulation 2014;130:2012-20.

21. Mehran R, Rao S V., Bhatt DL, et al. Standardized bleeding definitions for cardiovascular clinical trials: A consensus report from the bleeding academic research consortium. Circulation 2011;123:2736-47.

22. Stone GW, Lindenfeld JA, Abraham WT, et al. Transcatheter mitral-valve repair in patients with heart failure. N Engl J Med 2018;379:2307-18.

23. Grayburn PA, Sannino A, Packer M. Proportionate and Disproportionate Functional Mitral Regurgitation: A New Conceptual Framework That Reconciles the Results of the MITRA-FR and COAPT Trials. JACC Cardiovasc 
Imaging 2019;12:353-62.

24. Sanchis L, Freixa X, Regueiro A, et al. Safety and outcomes of MitraClip implantation in functional mitral regurgitation according to degree of left ventricular dysfunction. Rev Esp Cardiol (Engl Ed) 2020;73:530-5.

Cite this article as: Pascual I, Benito-González T, HernandezVaquero D, Estévez-Loureiro R, Lorca R, Garrote-Coloma C, Avanzas P, Gualis J, Adeba A, Pérez de Prado A, Morís C, Fernández-Vázquez F. Percutaneous treatment with Mitraclip for functional mitral regurgitation: medium-term follow up according to left ventricular function. Ann Transl Med 2020;8(15):959. doi: 10.21037/atm.2020.02.122 